\title{
Implementation of a training protocol on intrauterine device insertion for resident
}

\section{physicians}

\author{
Implementação de um protocolo de treinamento para inserção de dispositivo intrauterino para \\ médicos residentes
}

Implementación de un protocolo de capacitación sobre inserción de dispositivos intrauterinos para médicos residentes

Received: 04/08/2021 | Reviewed: 04/15/2021 | Accept: 04/14/2021 | Published: 04/27/2021

\author{
Sérgio Henrique Pires Okano \\ ORCID: https://orcid.org/0000-0002-6046-2659 \\ Universidade de São Paulo, Brazil \\ E-mail: sergio.okano@usp.br \\ Bruna Maria Bonatti da Silva Felipe \\ ORCID: https://orcid.org/0000-0002-9410-2221 \\ Universidade de São Paulo, Brazil \\ E-mail: brunabonatti44@gmail.com \\ Giordana Campos Braga \\ ORCID: https://orcid.org/0000-0002-0719-056X \\ Universidade de São Paulo, Brazil \\ E-mail: giordanacb@gmail.com
}

\begin{abstract}
Resumo
Objetivo: Implementar um protocolo de treinamento na inserção de dispositivo intrauterino (DIU) para médicos residentes a fim de melhorar o acesso das mulheres a este método. Métodos: A equipe identificou falta de acesso ao planejamento familiar no centro de saúde Vila Lobato, especialmente ao DIU, ocorreram apenas 15 inserções de DIU em 2015. Esta pesquisa de implementação avaliou e identificou as barreiras de acesso ao uso do DIU. Em seguida, os interessados e a equipe definiram o fluxo de acesso dos pacientes à unidade de saúde e, eventualmente, a formação oferecida aos médicos residentes em ginecologia e obstetrícia (GO) e medicina de família (FM). Esta é uma coorte retrospectiva das inserções de DIU realizadas por esses residentes entre 2016 e 2018. Resultados: 252 DIUs de cobre foram inseridos de 2016 a 2018 e houve um aumento progressivo no número de inserções (45 em 2016, $80 \mathrm{em} 2017$ e 126 em 2018). Foram observadas 34 (16,4\%) inserções inadequadas e $15(8,6 \%)$ expulsões. Não houve nenhum caso de perfuração uterina. Conclusão: A implementação do protocolo de inserção do DIU para residentes na atenção primária aumentou o número de inserção do DIU na unidade de saúde e pode ser uma estratégia para melhorar o acesso ao método anticoncepcional.
\end{abstract}

Palavras-chave: Contracepção; Dispositivos intrauterinos; Planejamento Familiar; Capacitação em serviço; Estratégia saúde da família.

\begin{abstract}
Objective: To implement a training protocol on intrauterine device (IUD) insertion for resident physicians to improve women's access to this method. Methods: The staff identified poor access to family planning, in Vila Lobato health center, specially to IUD, there were only 15 IUD insertions in 2015. This implementation research evaluated and identified the barriers of access to IUD use. Then, stakeholders and staff defined the access flow of patients to the health unit and, eventually, the training provided to resident physicians in gynecology and obstetrics (GO) and family medicine (FM). This is a retrospective cohort of the IUD insertions performed by residents between 2016 and 2018 . Results : 252 copper IUDs were inserted from 2016 to 2018 and there was a progressive increase in the number of insertions (45 in 2016, 80 in 2017, and 126 in 2018). Thirty-four (16.4\%) inadequate insertions and 15 (8.6\%) expulsions were observed. There was no case of uterine perforation. Conclusion: The implementation of the protocol on IUD insertion for residents in the primary care setting increased the local number of IUD insertion and might be a strategy to improve the access to the contraceptive method.
\end{abstract}

Keywords: Contraception; Intrauterine devices; Family planning; Inservice training; Family health strategy.

\section{Resumen}

Objetivo: Implementar un protocolo de capacitación sobre la inserción de dispositivos intrauterinos (DIU) para médicos residentes para mejorar el acceso de las mujeres a este método. Métodos: El personal identificó un acceso 
deficiente a la planificación familiar, en el centro de salud de Vila Lobato, especialmente al DIU, solo hubo 15 inserciones de DIU en 2015. Esta investigación de implementación evaluó e identificó las barreras de acceso al uso del DIU. Luego, las partes interesadas y el personal definieron el flujo de acceso de los pacientes a la unidad de salud $\mathrm{y}$, eventualmente, la capacitación brindada a los médicos residentes en ginecología y obstetricia (GO) y medicina familiar (FM). Esta es una cohorte retrospectiva de las inserciones de DIU realizadas por residentes entre 2016 y 2018. Resultados: se colocaron 252 DIU de cobre de 2016 a 2018 y hubo un aumento progresivo en el número de inserciones (45 en 2016, 80 en 2017 y 126 en 2018). Se observaron treinta y cuatro $(16,4 \%)$ inserciones inadecuadas y $15(8,6 \%)$ expulsiones. No hubo ningún caso de perforación uterina. Conclusión: La implementación del protocolo sobre inserción de DIU para residentes en el entorno de atención primaria aumentó el número local de inserción de DIU y podría ser una estrategia para mejorar el acceso al método anticonceptivo.

Palabras clave: Anticoncepción; Dispositivos intrauterinos; Planificación familiar; Capacitación en servicio; Estrategia de salud familiar.

\section{Introduction}

Access to effective contraceptive methods is a strategy to reduce unplanned pregnancy (Dibaba et al., 2013; Khan et al., 2019) and long-acting reversible contraceptives (LARC) is a cost-effective way to decrease the incidence of spontaneous abortion, ectopic pregnancy, inherent complications in pregnancy, maternal and perinatal mortality (Dibaba et al., 2013; Trussell et al., 2013). The prevalence of IUD insertion and use is widely varied worldwide. There is a greater number of users in Asia, especially among Chinese and Korean women, whereas in South America, only 5.5\% of women use this contraceptive method. In most countries, physicians regardless of their specialty are trained to insert IUD (Buhling, Zite, et al., 2014) and in some places, this practice is also conducted by nurses (Ouyang et al., 2019).

In the world, 1.1 billion women require family planning and about 270 million do not have access to this need, mainly in developing countries (Kantorová et al., 2020). The barriers associated with this difficulty in access include the limited option of contraceptives available; the lack of access to health systems, particularity for the youngest women with no children; women' insecurities about side effects; cultural and religious opposition; and poor quality of the services provided (WHO, 2020). Recent studies have demonstrated that there are not high failure rates, expulsion, infection and/or perforation in nulliparous women compared to parous women, regardless of age (Aoun et al., 2014). Even so, many professionals do not offer or recommend IUD for nulliparous women (Buhling, Hauck, et al., 2014) and do not conduct this practice in primary care setting. Over a decade, studies that evaluated the mechanism of action of copper IUD show that copper ions are toxic to sperms and there is no evidence of embryo destruction by the method (Ortiz \& Croxatto, 2007). However, due to misconceptions, myths, or religious matters, many women do not use IUD because they think it has an abortive effect (Martínez et al., 2019).

Training professionals in family planning services is an effective strategy to facilitate access to all contraceptive methods, including LARC (Ouyang et al., 2019). A systematic review aimed to explore the types and impact of IUCD insertion training for healthcare providers and conclude that increasing the number of healthcare providers skilled in IUD insertions in high-income countries will enhance access to this method of contraception and allow women greater contraceptive choice. The review evaluated the training for doctors, nurses and residents physicians, however, the review did not include Latina American countries (Ouyang et al., 2019). Few studies have reported training of resident physicians in family medicine for IUD insertion, most studies offer theoretical workshops on family planning (Geary et al., 2017; Jatlaoui et al., 2017; Stewart et al., 2016). An Australian cohort conducted in primary care assessed the competence of training in IUD insertion. Among them, 19 concluded the study, 96\% felt confident about LNG-IUS/IUD insertion in multiparous women and 46\%, in nulliparous (Stewart et al., 2016). Another study interviewed 1,221 American medical gynecologists regarding the use of LARC and the number of insertions performed in the clinical practice. Most (92\%) referred to training in medical residency for IUD insertion and a half (50.8\%) for the implant (Luchowski et al., 2014). There is a positive correlation between the number of IUD inserted in the previous year and undergoing treatment in residency (Luchowski et al., 2014). Continued education about implant and 
IUD is associated with the increase of LARC offer to the population (Luchowski et al., 2014; Ouyang et al., 2019; Romero et al., 2015).

In Brazil, IUD insertion is performed by trained gynecologists and general physicians. Ribeirão Preto is one of the largest cities in the countryside of the state of São Paulo (IBGE, 2019), with regionalization of care in health services. The highest number of IUD insertions often takes place in services linked to the university setting, which restricts the use of IUD to the population bounded to these places. The lack of information and limitation of access to LARC in specialized services hamper the offer of copper IUD, which is distributed for free.

The present study evaluates whether the implementation of IUD insertion training for resident physicians can improve the local access by women to this contraceptive method.

\section{Methodology}

Through the concepts of the Implementation Research in Health A Practical Guide (David et al., 2013), we discussed the possible barriers and constraints of access to intrauterine devices, in the city of Ribeirão Preto, particularly in the Centro Médico Social Comunitário Vila Lobato (CMSCVL). At first, it was investigated what possible barriers would keep women away from access to LARCS. In a second step, a flow of access to the copper IUD was proposed. Finally, doctors trained in the unit (residents in family health and gynecology and obstetrics) were trained to perform the insertions of this contraceptive, thus increasing the population's access to the copper IUD. These steps are described in detail below.

\section{Step 1: Identifying barriers of access to IUD in CMSCVL}

CMSCVL is a primary care service where resident physicians and medical students from the University of São Paulo (FMRP-USP) participate in internship programs and are trained in gynecology and obstetrics (GO) in primary health care. Over 50 years CMSCVL is a primary health service and the unit remained closed for 4 years for repair, resuming its work in April 2015. Although half of the women seen are at reproductive age, only 15 IUDs have been inserted throughout its reopening.

Besides copper IUD's high efficacy and its free distribution in the city of Ribeirão Preto, the rate of users was 5\%. The lack of information about health providers on how to obtain the method and the regionalization of care in the city were the first barriers identified (Table 1). Woman who desired for IUD insertion was referred to places where there would be physicians trained for the procedures, in secondary or tertiary care, creating difficulties in access in case of adverse events or intercurrences. Although there were gynecologists in primary care setting, few had the instrumental conditions for IUD insertion, or they did not want to conduct the procedure in this setting.

Table 1. Barriers of access to IUD.

\begin{tabular}{ll}
\hline Barriers of access to IUD & Strategy \\
\hline $\begin{array}{l}\text { Lack of information of } \\
\text { professionals about the } \\
\text { method }\end{array}$ & Training for the nursing team of the CMSC Vila Lobato in LARC, particularly copper IUD \\
\hline Regionalization & $\begin{array}{l}\text { Discussion with local management about the possibility of copper IUD insertion in women } \\
\text { not belonging to the covering area }\end{array}$ \\
\hline $\begin{array}{l}\text { Lack of professionals } \\
\text { trained in IUD insertion }\end{array}$ & Training for resident GO and Family Medicine physicians in IUD insertion \\
\hline $\begin{array}{l}\text { Difficulty in access to the } \\
\text { service in case of } \\
\text { intercurrences or adverse } \\
\text { effects }\end{array}$ & Access to women using copper IUD with no need for scheduling an appointment \\
\hline
\end{tabular}




\section{Step 2: Defining IUD access flow}

The implementation of training for medical professionals in the CMSCVL internship program was proposed to favor access to LARC, mainly to copper IUD. For that, local managers were engaged in the process and consented to the training implementation, allowing, as well, that women from other locations could have IUD inserted in the CMSCVL unit, despite the regionalization. With implementation process, the unit would be the reference for follow up, intercurrences or adverse effects after insertion. Although there are several primary care gynecologists in Ribeirão Preto-SP, many of them do not perform IUD insertion and there is difficulty in accessing possible intercurrences, which are not scheduled.

There was a family planning training for the team of CMSCVL health providers on LARC, especially on copper IUD to improve the attention to the spontaneous demands of women who desired for contraception, even if they did not belong to the coverage area of the unit. This training was also extended to family planning groups, where the training team introduced the method, failure rates, and its advantages and disadvantages, for instance, over definite methods, such as tubal ligation and vasectomy. A special schedule was created for IUD insertion and who wish a contraceptive counseling. Table 1 shows the barriers found and strategies implemented to improve IUD access.

\section{Step 3: Implementing training in IUD insertion for residents}

Training for the medical resident was held at two different times and was a mandatory condition to the release for the insertion by the medical professional. First, a theoretical class was given on-site or through a video in the residency program. The second moment happened immediately before insertioan in the patient when the insertion technique was reviewed in an anatomical model by the resident physician in Family Medicine (FM) and Gynecology and Obstetrics (GO) at CMSCVL. This training aimed to improve the knowledge of the medical resident before the insertion, evaluating and correcting the technique.

This is a retrospective cohort were performed in city of Ribeirão Preto, Brazil, from January 2016 to December 2018. During the internship supervised by the preceptor, the training for GO and FM residents took place, where they performed the insertion of IUD in women who desired this contraceptive method (Supplementary Material 2). The IUD insertions performed tby residents were analyzed and data collection was made through the review of medical records. The study was approved by the institutional review board of HC-FMRP-USP.

All IUD inserted at CMSCVL from January 2016 and December 2018 were considered for evaluation. We excluded from the analysis: cases where two devices were dispensed for the same patient when it happened on the same day; the insertions not performed due to clinical issues detected during the procedure (unfavorable uterine size in hysterometry, cervical canal stenosis, e.g.); insertions performed by the staff; and incomplete medical records or without information about the patient's follow-up. Sociodemographic and obstetrics characteristics were assessed in category variables at baseline from medical records. After the procedure was concluded, an ultrasound was scheduled to evaluate if the insertion was adequate or inadequate, it was considered adequate when IUD was within the uterine cavity. Follow-up was conducted in 40 days, 6 and 12 months after IUD insertion.

Category variables are represented in absolute and relative frequencies. The paired T-test was used to compare the quantitative variables between the two groups of resident physicians, using R x64 software 3.3.2, with a significance level of $5 \%$.

\section{Results}

Two hundred and fifty-two copper IUDs were dispensed by the pharmacy service from 2016 to 2018. After the implementation of the training for resident physicians, there were progressive IUD insertions in the service: 45 in 2016, 80 in 2017, and 126 in 2018. Twenty-three insertions were excluded because they were performed by the preceptors, or for technical 
issues (hysterometry greater than $11 \mathrm{~cm}$ and stenosis of the cervix internal orifice) and 4 IUD were contaminated, then they were not inserted. Of the 229 IUD inserted by resident physicians, 159 patients returned to follow up after 12 months and 22 medical records were not found or had incomplete information (Figure 1).

Figure 1. Flowchart.

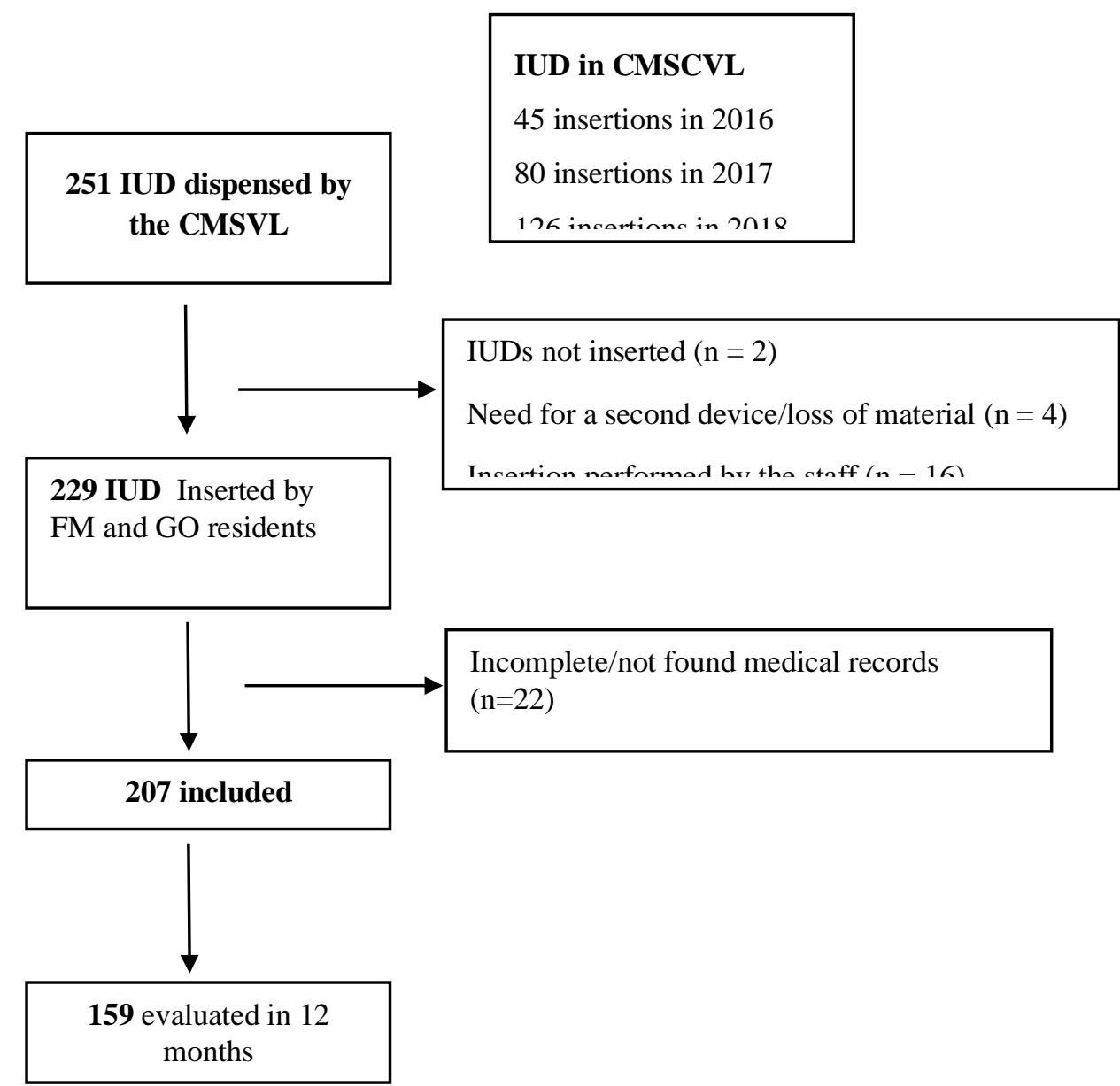

IUD- Intrauterine device; CMSCVL - Centro Médico Social e Comunitário Vila Lobato; FM - Family Medicine; GO - Gynecology and Obstetrics. Source: Authors.

The 207 women whose IUD insertion was analyzed were at the median age of 27.6 years \pm 6.5 years, 68 (37.6\%) were married, $54(26 \%)$ presented with comorbidities, such as thrombophilia, hypertension, and/or diabetes. Most had previous labor (71\%), 66 (31.8\%) underwent previous cesarean section, $30(14.4 \%)$ had a previous miscarriage, and 181 women $(87.4 \%)$ denied the use of alcohol, drugs, or tobacco (Table 2). During this period, 74 residents took part in the training for IUD insertion in the unit. In one year, the number of insertions per resident was in the maximum 8, with a median of 3 insertions a year per resident. Thirty-four (16.4\%) inadequate insertions and 15 (8.6\%) expulsions were observed in the 12 month follow-up. There was not any case of uterine perforation during the study. There was no difference in the performance of insertions when comparing GO and Family Medicine residents ( $\mathrm{p}=0.92)$ (Table 3). 
Table 2. Baseline characteristics of women who inserted IUD in medical residents training protocol.

\begin{tabular}{|l|l|}
\hline Characteristic & $\begin{array}{l}\text { IUD inserted in } \\
\text { CMSCVL (n= 207) }\end{array}$ \\
\hline Age (years) [mean (SD)] & $27.6(6.5)$ \\
\hline Comorbidities [\% (n)] & $54(26 \%)$ \\
\hline Smokers [\% (n)] & $157.2 \%)$ \\
\hline Parity [\% (n)] \\
$\mathbf{0}$ & $60(29 \%)$ \\
$\geq \mathbf{1}$ & $147(71 \%)$ \\
\hline Previous cesarean [\% (n)] & $66(31.8 \%)$ \\
\hline $\begin{array}{l}\text { Marital status [\% (n)] } \\
\text { Single } \\
\text { Married }\end{array}$ & $129(62.3 \%)$ \\
\hline $\begin{array}{l}\text { Abortion } \\
\mathbf{0}\end{array}$ & $78(37.7 \%)$ \\
$\mathbf{1}$ & $177(85.5 \%)$ \\
\hline
\end{tabular}

IUD: Intrauterine device, SD: Standard Deviation, CMSCVL: Centro Medico Social e Comunitário Vila Lobato. Source: Authors.

Table 3. Performance of intrauterine device insertion by resident physiscians.

\begin{tabular}{|l|l|l|l|}
\hline $\begin{array}{l}\text { IUD inserted } \\
(\mathbf{n}=\mathbf{2 0 7})\end{array}$ & $\begin{array}{l}\text { IUD inserted by } \\
\text { GO residents } \\
(\mathbf{n}=\mathbf{1 0 9})\end{array}$ & $\begin{array}{l}\text { IUD inserted by FM } \\
\text { residents } \\
(\mathbf{n}=\mathbf{9 8})\end{array}$ & *p \\
\hline Inappropriate insertion & 17 & 17 & 0.921 \\
\hline Expulsion & 8 & 7 & 0.924 \\
\hline Perforation & 0 & 0 & \\
\hline
\end{tabular}

IUD: Intrauterine device. GO: Gynecology and obstetrics. FM: Family Medicine. *T Student test. Source: Authors.

The Vila Lobato health unit is currently a reference in the city of Ribeirão Preto to LARC methods, cases from all over the city are referred to the unit because of this implementation and availability of trained and in training professionals.

\section{Discussion}

The implementation of the training protocol for GO and FM residents made access easier for women in CMSCVL and the strategy increased IUD insertions over the three years of evaluation.

Theoretical and practical training using anatomic models immediately after IUD insertion is an easily applicable reproducible standardized teaching methodology. Training in an anatomical model of the female pelvis has been previously used, before supervised insertion or in continuing education programs for physicians and nurses (Kemeny et al., 2016; Nippita et al., 2015; Stewart et al., 2016). A randomized study used video classes for training residents of the FM program. Video training showed to be an effective method to provide comprehensive training for IUD insertion and gaining psychomotor skills (performance component); however, technique and performance were evaluated only in anatomical models (Garcia-Rodriguez \& Donnon, 2016, p.). It is more frequent that IUD training is held at hospital institutions, linked to universities or family planning clinics (Dermish et al., 2016; Laporte et al., 2020; Thompson et al., 2016).

Few studies reported training in IUD insertion for resident physicians in the primary care setting or in Latin America, including performance evaluation (Geary et al., 2017; Jatlaoui et al., 2017; Laporte et al., 2020; Stewart et al., 2016). In primary care cohort, trained FM physicians said that they felt confident about the training, but the obstacle reported for IUD offer and insertion was the payment, which was not cost-effective in the practice (Stewart et al., 2016). We observed that the training in IUD insertion during residency, regardless of the teaching method, and the continued education have a positive 
correlation with LARC offer to the population (Luchowski et al., 2014). Few studies evaluate training of resident physicians on IUD insertion in primary care. This is the first national study on the implementation of training on IUD for residents to improve women's access to IUD in the primary care setting.

The training was offered to residents from GO and FM, which similar rates of expulsion and inadequate insertions were shown. A recent Brazilian studied conducted at the University of Campinas shows similar performance results when IUD or LNG-IUS were inserted by medical residents, generalists, or nurses, with no differences in expulsion rates or removal for personal reasons (Laporte et al., 2020). The expulsion rate (8.6\%) was higher than the one found in the literature; however, it can be deemed acceptable once we are in training service, and more than $70 \%$ of women that desire for IUD have access to the method (Trussell, 2011). Perforation rates are rare in IUD insertion (1.4 out of 1000 insertions) and there was no perforation in this training protocol (Modesto et al., 2014).

In Southeast of Brazil, the women users of the public health system are mostly black women, with elementary education and low income (Peipert et al., 2011). Some local barriers of access to copper IUD have been overcome, favoring family planning in primary care. Some positive aspects of this developed protocol are the structured and systematic standardization for IUD insertion training physicians, with low cost and reproductibility.

As limitations of the study, $10 \%$ of the information of medical records were lost because they were not stored in electronic forms, decreasing the size of the sample of this retrospective cohort in addition to discontinuation of the 12-month follow-up after insertion in 48 women. On the other hand, more than $70 \%$ of women who underwent copper IUD insertion came for at least one visit after the 12-month insertion follow-up, data that reinforces the high rate of continuity of the method, even though IUD was inserted by in training physicians (Modesto et al., 2014; Peipert et al., 2011).

Given the turnover of residents at the service, general gynecological care, prenatal, and family planning, the number of insertions was variable per resident, with a median of three insertions. The low number of insertions per resident physician a limitation of our study, nevertheless, CMSCVL is the first contact of these physicians with IUD insertion who continue to perform the procedure in the upcoming years of their education. A study with 19 family physicians had a median of 4.5 insertions, most inserted LNG-IUS and 96\% felt confident about the insertion of LNG-IUS/IUD in multiparous women and $46 \%$, in nulliparous after 12 months of the training (Stewart et al., 2016). In the training protocol, residents inserted IUD in $29 \%$ nulliparous women and $31 \%$ with prior cesarean section without causing great difficulties for trained physicians.

\section{Authors' conclusion}

The training for residents in IUD insertion at the health unit has enabled the increase in the number of IUD offered to women with no significant differences among the trained teams. The implementation of the protocol on IUD insertion for residents in primary care might be a strategy to demystify the procedure complexity and increase the access to this LARC to women, promoting gender equity and reproductive planning.

\section{References}

Aoun, J., Dines, V. A., Stovall, D. W., Mete, M., Nelson, C. B., \& Gomez-Lobo, V. (2014). Effects of age, parity, and device type on complications and discontinuation of intrauterine devices. Obstetrics and Gynecology, 123(3), 585-592. https://doi.org/10.1097/AOG.0000000000000144

Buhling, K. J., Hauck, B., Dermout, S., Ardaens, K., \& Marions, L. (2014). Understanding the barriers and myths limiting the use of intrauterine contraception in nulliparous women: Results of a survey of European/Canadian healthcare providers. European Journal of Obstetrics, Gynecology, and Reproductive Biology, 183, 146-154. https://doi.org/10.1016/j.ejogrb.2014.10.020

Buhling, K. J., Zite, N. B., Lotke, P., Black, K., \& INTRA Writing Group. (2014). Worldwide use of intrauterine contraception: A review. Contraception, 89(3), 162-173. https://doi.org/10.1016/j.contraception.2013.11.011 
David H P, Nhan TT, Taghreed A.Alliance for Health Policy and Systems Research, World Health Organization. Implementation Research in Health-A Practical GUide. 2013. Available: Https://www.who.int/alliance-hpsr/resources/implementationresearchguide/en/. (n.d.).

Dermish, A., Turok, D. K., Jacobson, J., Murphy, P. A., Saltzman, H. M., \& Sanders, J. N. (2016). Evaluation of an intervention designed to improve the management of difficult IUD insertions by advanced practice clinicians. Contraception, 93(6), 533-538. https://doi.org/10.1016/j.contraception.2016.01.011

Dibaba, Y., Fantahun, M., \& Hindin, M. J. (2013). The effects of pregnancy intention on the use of antenatal care services: Systematic review and metaanalysis. Reproductive Health, 10, 50. https://doi.org/10.1186/1742-4755-10-50

Garcia-Rodriguez, J. A., \& Donnon, T. (2016). Using Comprehensive Video-Module Instruction as an Alternative Approach for Teaching IUD Insertion. Family Medicine, 48(1), 15-20.

Geary, M., Prifti, C., \& Bachorik, A. (2017). Residency Training in Long-Acting Reversible Contraceptive Methods. JAMA Internal Medicine, 177(7), 10611062. https://doi.org/10.1001/jamainternmed.2017.2101

IBGE, 2019. Ribeiraão Preto-SP. https://www.ibge.gov.br/cidades-e-estados/sp/ribeirao-preto.html, Acesso em 24/02/2020. (n.d.).

Jatlaoui, T. C., Riley, H. E. M., \& Curtis, K. M. (2017). The safety of intrauterine devices among young women: A systematic review. Contraception, 95(1), 17-39. https://doi.org/10.1016/j.contraception.2016.10.006

Kantorová, V., Wheldon, M. C., Ueffing, P., \& Dasgupta, A. N. Z. (2020). Estimating progress towards meeting women's contraceptive needs in 185 countries: A Bayesian hierarchical modelling study. PLOS Medicine, 17(2), e1003026. https://doi.org/10.1371/journal.pmed.1003026

Kemeny, F., Digiusto, E., \& Bateson, D. (2016). Insertion of intrauterine contraceptive devices by registered nurses in Australia. The Australian \& New Zealand Journal of Obstetrics \& Gynaecology, 56(1), 92-96. https://doi.org/10.1111/ajo.12427

Khan, M. N., Harris, M. L., Shifti, D. M., Laar, A. S., \& Loxton, D. (2019). Effects of unintended pregnancy on maternal healthcare services utilization in low- and lower-middle-income countries: Systematic review and meta-analysis. International Journal of Public Health, 64(5), 743-754. https://doi.org/10.1007/s00038-019-01238-9

Laporte, M., Becerra, A., Castro, L., Veiga, N., Espejo-Arce, X., \& Bahamondes, L. (2020). Evaluation of clinical performance when intrauterine devices are inserted by different categories of healthcare professional. International Journal of Gynaecology and Obstetrics: The Official Organ of the International Federation of Gynaecology and Obstetrics. https://doi.org/10.1002/ijgo.13396

Luchowski, A. T., Anderson, B. L., Power, M. L., Raglan, G. B., Espey, E., \& Schulkin, J. (2014). Obstetrician-gynecologists and contraception: Long-acting reversible contraception practices and education. Contraception, 89(6), 578-583. https://doi.org/10.1016/j.contraception.2014.02.004

Martínez, F., Parra, I., Andeyro, M., Cristobal, I., \& Quílez, J. C. (2019). Barriers to the use of intrauterine devices among healthcare professionals: Evidence against misconceptions. Progresos de Obstetricia y Ginecologia, 62(1), 63-71. Embase. https://doi.org/10.20960/j.pog.00171

Modesto, W., Bahamondes, M. V., \& Bahamondes, L. (2014). A randomized clinical trial of the effect of intensive versus non-intensive counselling on discontinuation rates due to bleeding disturbances of three long-acting reversible contraceptives. Human Reproduction (Oxford, England), 29(7), 1393-1399. https://doi.org/10.1093/humrep/deu089

Nippita, S., Haviland, M. J., Voit, S., Peralta, J. P., Hacker, M. R., \& Paul, M. E. (2015). Comfort and Competency With Intrauterine Contraception Insertion: A Randomized Controlled Trial [226]. Obstetrics \& Gynecology, 125, 73S-74S. https://doi.org/10.1097/01.AOG.0000463151.05205.32

Ortiz, M. E., \& Croxatto, H. B. (2007). Copper-T intrauterine device and levonorgestrel intrauterine system: Biological bases of their mechanism of action. Contraception, 75(6 Suppl), S16-30. https://doi.org/10.1016/j.contraception.2007.01.020

Ouyang, M., Peng, K., Botfield, J. R., \& McGeechan, K. (2019). Intrauterine contraceptive device training and outcomes for he althcare providers in developed countries: A systematic review. PloS One, 14(7), e0219746. https://doi.org/10.1371/journal.pone.0219746

Peipert, J. F., Zhao, Q., Allsworth, J. E., Petrosky, E., Madden, T., Eisenberg, D., \& Secura, G. (2011). Continuation and satisfaction of reversible contraception. Obstetrics and Gynecology, 117(5), 1105-1113. https://doi.org/10.1097/AOG.0b013e31821188ad

Romero, D., Maldonado, L., Fuentes, L., \& Prine, L. (2015). Association of reproductive health training on intention to provide services after residency: The family physician resident survey. Family Medicine, 47(1), 22-30.

Stewart, M., Digiusto, E., Bateson, D., South, R., \& Black, K. I. (2016). Outcomes of intrauterine device insertion training for doctors working in primary care. Australian Family Physician, 45(11), 837-841.

Thompson, K. M. J., Rocca, C. H., Kohn, J. E., Goodman, S., Stern, L., Blum, M., Speidel, J. J., Darney, P. D., \& Harper, C. C. (2016). Public Funding for Contraception, Provider Training, and Use of Highly Effective Contraceptives: A Cluster Randomized Trial. American Journal of Public Health, 106(3), 541546. https://doi.org/10.2105/AJPH.2015.303001

Trussell, J. (2011). Contraceptive failure in the United States. Contraception, 83(5), 397-404. https://doi.org/10.1016/j.contraception.2011.01.021

Trussell, J., Henry, N., Hassan, F., Prezioso, A., Law, A., \& Filonenko, A. (2013). Burden of unintended pregnancy in the United States: Potential savings with increased use of long-acting reversible contraception. Contraception, 87(2), 154-161. https://doi.org/10.1016/j.contraception.2012.07.016

WHO: Family planning/contraception methods. 2020. Available in: Https://www.who.int/news-room/fact-sheets/detail/family-planning-contraception. 